\title{
Quality and Safety of the National Blood Supply: A Priority for Action - Subregional Overview Bulgaria, Croatia, Romania, Serbia and Montenegro
}

\author{
Valentina Hafner ${ }^{a}$ Alina Dobrota ${ }^{b}$ Dorotea Sarlija ${ }^{c}$ Gordana Rasovic $^{d}$ \\ a Division of Country Health Systems, WHO Regional Office for Europe, Copenhagen, Denmark \\ ${ }^{b}$ Regional Blood Transfusion Center, Constanta, Romania \\ c National Institute of Blood Transfusion, Zagreb, Croatia \\ ${ }^{\mathrm{d}}$ Center for Blood Transfusion - Clinical Center, Podgorica, Republic of Montenegro
}

\section{Key Words}

Blood service · Quality standards · Safe blood supply

\section{Summary}

Blood transfusion services across Europe show varying levels of development, financing, and support. The region, however, shares common characteristics, such as epidemiological background, a decreasing number of blood donations, and increasingly sophisticated technologies of testing and therapeutic procedures. Furthermore, the constantly enlarging EU and the requirements of dedicated directives demand that increased attention be given by member states to the harmonization of blood transfusion practices and safety standards. The current review of blood services in selected countries (EU accession, pre- and pro-accession status) shows that blood safety is a recognized political priority and that important efforts have been initiated to update legislation and to restructure services on a national basis within the health system's framework.

\section{Introduction}

Common challenges across Europe, such as demographic aging, an increasing number of HIV/AIDS cases and growing cross-border movement, have a direct impact on the safety and availability of the blood supply at both the national and the regional level. The constantly enlarging European Union

\section{Schlüsselwörter}

Blutspendedienst . Qualitätsstandards .

Sichere Blutversorgung

\section{Zusammenfassung}

Die Blutspendedienste in Europa unterscheiden sich deutlich hinsichtlich ihrer Entwicklung, ihrer Finanzierung und ihrer Unterstützung. In Bezug auf den epidemiologischen Hintergrund, die abnehmende Zahl an Blutspenden und die zunehmend ausgefeilteren Technologien zur Testung und Therapie zeigen, die europäischen Blutspendedienste haben auch Gemeinsamkeiten. Darüber hinaus verlangen die zunehmende Vergrößerung der EU und die Anforderungen von bestimmten Direktiven, dass die Mitgliedstaaten der Harmonisierung von Bluttransfusionspraktiken und Sicherheitsstandards stärkere Aufmerksamkeit widmen. Die vorliegende Übersicht von Blutspendediensten in verschiedenen Ländern, in denen der EU-Beitritt bereits erfolgt ist oder unmittelbar bevorsteht oder die eine EU-Mitgliedschaft anstreben, zeigt, dass die Blutsicherheit als politische Priorität erkannt worden ist und dass wichtige Weichenstellungen vorgenommen wurden, um die Gesetzgebung zu aktualisieren und die Blutspendedienste auf nationaler Ebene innerhalb des Gesundheitssystems zu restrukturieren.

which imposes mandatory blood safety requirements (Directives 2002/98/EC, 2004/33/EC, 2005/61/EC) [1] is an important factor in the harmonization of blood transfusion practices as well as quality and safety requirements among member states. The current review of blood services is focused on selected Central Eastern European countries in accession (Bulgaria, Romania), pre-accession (Croatia) and pro-accession (Repub-

\begin{tabular}{ll}
\hline KARGER & $\oplus$ 2006 S. Karger GmbH, Freiburg \\
Fax +497614520714 & Accessible online at: \\
$\begin{array}{l}\text { E-mail Information@Karger.de } \\
\text { www.karger.com }\end{array}$ & www.karger.com/tmh
\end{tabular}

\section{KARGER}

www.karger.com
Dr. Valentina Hafner

Quality of Health Systems Programme, Division of Country Health Systems WHO Regional Office for Europe

8, Scherfigsvej, 2100 Copenhagen, Denmark

E-mail vha@euro.who.int 
Table 1. General statistics

\begin{tabular}{lrrll}
\hline Country & Size, $\mathrm{km}^{2}$ & Population & $\begin{array}{l}\text { Median age, } \\
\text { years }\end{array}$ & $\begin{array}{l}\text { Gross domestic product (GDP) } \\
\text { USD per capita 2003 }\end{array}$ \\
\hline Bulgaria & 111,000 & $7,845,841$ & 39.1 & 2,539 \\
Croatia & 56,542 & $4,437,460$ & 38.9 & 6,479 \\
Romania & 238,500 & $21,673,328$ & 34.7 & 2,619 \\
Serbia & 77,474 & $7,498,000$ & 35.4 & 2,528 \\
Montenegro & 13,812 & 620,145 & 35.4 & NA \\
\hline
\end{tabular}

lic of Serbia, Republic of Montenegro) for EU integration. It focuses on national specifics (including legal and regulatory framework), quality specifics (including standards and accreditation), and additional quality and safety issues (including hemovigilance).

\section{National Specifics}

The selected countries range from medium to high in the human development index category (table 1) and during the last 10 years have undergone (still ongoing) major restructuring at the heath system level [2]. The health care reform underway in these areas and the evolving health care expenditure are directly reflected in the development and functioning of the national blood services. Blood safety is a recognized priority at government level in all 5 countries, and the blood services are under the authority of the respective Ministries of Health. Efforts have been undertaken to revise the existing structure of the blood service on a national basis according to recognized international recommendations $[1,3,4]$. To provide a supportive framework for the process, the existing dedicated laws and regulations have been updated or considered for revision. National expert committees function as advisory bodies to the Ministry of Health and are involved in the process of reform. The budgetary provision for the service is complemented from various sources and seems to require increased attention to meet current needs for development.

All countries have a legal and regulatory framework for the blood service [5]. Bulgaria, Romania and Croatia have updated their legislation to support restructuring of their blood services and to comply with recent developments in the field EU Directive 2002/98/EC [1] and related requirements. Additional regulatory acts in each country complete the existing legal provisions for blood quality and safety. Bulgarian law on blood, blood donation and blood transfusion (2003), Romanian law for the organization of blood transfusion services, blood donation and blood components of human origin, as well as quality and safety requirements for their therapeutic use (2005), and Croatian law on blood supply (2005), all regulate the reorganization of the blood service on a national basis and enshrine the principles of voluntary non-remunerated blood donation, protection of donors and recipients, and equitable access to and rational use of blood transfusion, while aiming for national self-sufficiency. Serbia and Montenegro have initiated the process of revising and updating existing laws and regulations covering the blood services towards national coordination of the blood service and compliance with EU-dedicated directives. In 2005, a national strategy for providing adequate quantities of safe blood and blood products was adopted in Serbia as a significant step forward in this process.

It is important to underline that all the above-mentioned countries are members of the South East European health network and have signed the Dubrovnik Pledge [6] (2001) developed within the Stability Pact - Social Cohesion Initiative. Supported jointly by the World Health Organization (WHO) Regional Office for Europe and the Council of Europe (COE), this initiative of the Ministries of Health from 8 South Eastern European countries is focused on vulnerable populations, access to health and regional collaboration. The other 4 beneficiaries are Albania, Bosnia and Herzegovina, The former Yugoslav Republic of Macedonia and Moldova. Blood safety has been one of the recognized regional health priorities for action by Health Ministers from all participant states. Component one of the blood safety project is aimed to support development/ update of blood safety national policies in line with EU directives, WHO and COE recommendations $[1,3,4]$, and to set subregional strategic priorities for action (expected for completion in 2006) [7].

Response and efficacy of health systems are related to organization and not simply finances. The current structure of the blood service shows an interesting range of national constellations, with blood services as: i) stand-alone institutions (Romania), ii) hospital-based and stand-alone institutions (Bulgaria, Croatia, Serbia), or iii) hospital-based only institutions (Montenegro). The total number of blood service facilities ranges from 42 blood establishments and several blood banks (Romania), to 10 hospital-based facilities with mixed activities (Montenegro). Even if correlations are drawn with the population and geographical size of these countries as well as with health care service development, the need to rethink the number, distribution and responsibilities of existing blood service facilities requires immediate attention. Such a process has been started in Bulgaria (with restructuring of about 5 regional centers under the coordination of the National Center for Hematology and Transfusiology), and is under consideration in the other countries. 
Table 2. Quality policies, licensing and accreditation

\begin{tabular}{|c|c|c|c|}
\hline Country & Quality policy & BS licensing & BS accreditation \\
\hline Bulgaria & national policy 2005 & Ministry of Health & $\begin{array}{l}\text { Accreditation committee of } \\
\text { the Ministry of Health }\end{array}$ \\
\hline Croatia & $\begin{array}{l}\text { no national policy } \\
\text { institutional level, in part }\end{array}$ & $\begin{array}{l}\text { Agency for Medicinal } \\
\text { Products and Medical } \\
\text { Devices }\end{array}$ & $\begin{array}{l}\text { Agency for accreditation } \\
\text { (for testing procedures) }\end{array}$ \\
\hline Romania & $\begin{array}{l}\text { no national policy } \\
\text { institutional level, in part }\end{array}$ & State Sanitary Inspection & \\
\hline Serbia & institutional level, in part & & \\
\hline Montenegro & no national policy & Ministry of Health & \\
\hline
\end{tabular}

$\mathrm{BS}=$ Blood service

\section{Quality Specifics}

Harmonization of quality and safety standards requires an adequately regulated, organized, budgeted and staffed blood service in appropriately designed, maintained and equipped facilities. Regulations work as a sustainable force for change, and parts of the current laws oversee implementation of several quality interventions $[8,9]$.

Quality policies as such have been commonly agreed and adopted in Bulgaria (2005). Due to the current lack of a nationally coordinated blood service in Croatia, Serbia and Montenegro, quality policies have been reported to exist only at institutional level in some of the blood service facilities. In Romania, a bottom-up approach to implementation of a quality framework is being initiated $[5,7]$. The recently adopted Bulgarian medical standard of transfusion hematology covers all the activities of blood donation and transfusion. Good manufacturing practices have been introduced in the blood service following the updated legal requirements. The COE 'Guide to the Preparation and Quality Assurance of Blood Components', in its various editions has been translated into the national languages and is used in current practice as technical reference. Quality manuals are under development in Bulgaria and Romania, and are being considered in Croatia, Serbia and Montenegro (table 2).

There is no uniform approach to licensing and accreditation of blood transfusion institutions in the selected countries. Accreditation of such institutions is mandatory by law in Bulgaria, and is performed by a specialized body (accreditation committee) of the Ministry of Health. The other countries report licensing procedures to be in place (e.g. State Sanitary Inspection in Romania, Agency for Medicinal Products and Medical Devices in Croatia, Ministry of Health in Montenegro). Health professionals are licensed by the professional bodies in their countries at regular intervals (e.g. every 5 years in Romania, every 6 years in Croatia). They are subject to periodic training as part of an apparently mandatory continuous education program.

Auditing is not yet a general policy nor are a documented audit schedule or trained auditors available. According to the new amendments to the law (still in parliament), blood trans- fusion centers will be subject to inspection by the National Drug Agency. In Croatia, Serbia and Montenegro, a partial audit process seems to be in place. In all countries, the National Medicine Agencies validate blood products resulting from industrial fractionation.

The introduction of quality management systems along the blood transfusion chain and quality standards for adequate use of blood at the clinical site are key components of the Bulgarian national program 'Blood Safety 2005-2010' and its subsequent plan of action. National quality management systems are not yet defined in Romania (established as a priority in the national blood program and plan of activities), are defined in part in Croatia, while a quality management system will be implemented in all transfusion services in Serbia (in accordance with the defined National Strategy).

It is a recognized fact that the quality of the blood supply depends on the quality and availability of donors. In the selected countries, blood donation is mainly voluntary and non-remunerated $[5,8]$. The percentage of blood donors in the general population mirrors public perception and involvement in the blood donation/transfusion process. The figure varies from 1.75\% (Romania), 1.91\% (Bulgaria), 2.1\% (Montenegro) and $3.1 \%$ (Serbia), to $3.6 \%$ (Croatia). It also reflects the funding available for blood donation promotion activities as well as for dedicated staff.

The World Blood Donor Day event, initiated as an annual celebration following World Health Assembly 2005, is expected to further enhance the degree of information, awareness and social sense of responsibility and recognition of the importance of voluntary non-remunerated blood donation. It is also expected to complement and sustain the momentum of local activities for education, promotion and retention of blood donors. The motto of the World Blood Donor Day event on 14th June 2006 was 'Celebrating the Gift of Blood' [3, 10].

\section{Additional Quality and Safety Issues}

The adequate use of blood, blood components and products at the clinical level as one of the key links in the blood chain re- 
Table 3. Hemovigilance: national systems, error reporting, supportive information technologies (IT)

\begin{tabular}{llll}
\hline Country & National hemovigilance & Error reporting & IT systems \\
\hline Bulgaria & mandatory by law (1999, updated 2005) & included in the clinical guidelines & NCHT + 5 RC \\
Croatia & mandatory / voluntary & documented strategy & NIBT + $\mathrm{BB}$ \\
Romania & stipulated by law/ under development & quoted in the regulations & under development \\
Serbia & no national approach & annual reports & no documented protocols \\
Montenegro & no national approach & & \\
\hline
\end{tabular}

NCHT = National Center for Hematology and Transfusiology; RC = regional center; CIBT = Croatian Institute for Blood Transfusion; BB = blood banks; NIHT = National Institute for Hematology and Transfusion; BC = blood centers. quires quality and safe blood components and products and a harmonized therapeutic approach based on best available evidence, responding to patient needs [3-5]. Clinical guidelines for the use of blood and blood components (COE recommendations, WHO guide and AABB (American Association of Blood Banks) standards) appear to be available in the countries targeted by this analysis, however, their degree of use and availability at local level is variable [11]. National guidelines are available in Bulgaria (since 1996 and currently being updated), and also in Croatia, Serbia and Montenegro. Romania has translated into the national language the WHO Clinical Use of Blood Handbook and is now preparing a national guide. The main challenge recognized by all countries is the actual implementation of the guidelines, be they of national or international origin. A national hemovigilance system and functional hospital transfusion committees (HTC) monitoring the use of blood are expected to reverse the current trends and strengthen transfusion practice and patient safety [2,7]. At present, hemovigilance is not operational at national level. With legal and/or regulatory requirements in place, actual implementation demands a commonly agreed taxonomy, appropriate communication and supportive mechanisms based on a reporting and learning culture. A hemovigilance system is required by law in Bulgaria and Croatia, and stipulated in Romania. Common forms related to ordering, administration and follow-up of blood transfusion are in use, following the same general data requirements (patient, diagnostics, doctor, service etc). These are either standardized at national level (Bulgaria, Serbia and Montenegro) or are subject to formatting variations according to generating hospital and applied procedure (Croatia and Romania). The responsibility for prescription, ordering and administration of transfusion is borne by the physician in all countries.

HTC have been established in major hospitals and monitor the use of blood and blood components according to the legal provisions in place (Bulgaria, Croatia, Romania). Their degree of functionality is again variable. For example, HTC are in charge of periodic control of transfusion practices in all major Bulgarian hospitals and must produce annual reports. The information these reports provide, however, is often of limited relevance. Romanian hospital hemovigilance committees have a low capacity for operation, and communication between the blood service and hospitals appears to be slow. An increasingly consistent approach is under development as part of the ongoing legal updating process. It is to be mentioned that Romania (observer) and Croatia (member) participate in the European hemovigilance network The process of introducing hospital transfusion/hemovigilance committees has been initiated in Serbia, with committees being established, and in Montenegro, with committees being considered.

Error reporting is generally focused on serious adverse events or failures along the blood chain. The management of adverse reactions, including reporting, is included in the clinical guidelines in Bulgaria. Written documentation is expected to be available with the full description and outcome of adverse events (table 3). Croatia has a documented strategy for error reporting and handling, with failures reported to the Agency for Medicinal Products and Medical Devices. The mandatory reporting system for serious adverse events related to drugs and medical products, however, did not prove successful. National data on errors, complaints, and materio-vigilance has been collected by the Croatian Institute for Blood Transfusion since 1999 on a voluntary basis, and a voluntary register for transfusion reactions is led by the Clinical Hospital Rebro in Zagreb. The Romanian reporting schemes for adverse events need to be developed in a standardized manner. Severe adverse events are subject to mandatory reporting through the National Institute of Hematology and Transfusion to the Institute of Legal Medicine. The new blood law includes important aspects regarding reporting procedures and hemovigilance systems. The approach to reporting is heterogeneous in both Serbia and Montenegro. Annual reports on adverse reactions to transfusion are prepared by each blood center in Serbia. The epidemiological service is in charge of the follow-up of infectious agent transmission through blood. Montenegro has no documented protocol for error reporting. Investigating adverse reactions is difficult due to under-reporting, frequent inadequately filled out ordering forms and lack of documentation on the outcome of transfused units.

Comprehensive supportive information technology systems do not appear to exist on a national scale in any of the selected countries. Introduction of national information technology (IT) systems is either foreseen or considered within the frame- 
work of the 'blood service reform'. In Bulgaria, the National Center for Hematology and Transfusiology is linked with the 5 regional centers. Barcode labeling has been introduced in the regional centers only, and internal computerized organization using ISBT 128 is foreseen. In Romania, only the National Institute for Hematology and Transfusion and 3 additional blood centers have computer systems in place. The implementation of a national IT transfusion network is anticipated during 2006. In addition to the computer system at the Croatian Institute for Blood Transfusion, 9 hospital blood banks have a computerized system for the clinical site at national level. Serbia and Montenegro have no IT network. New software for blood services should be implemented in Serbia by June 2006. Contingency plans/emergency procedures are developed at different levels by each country. At present, importation of blood and blood components can be performed only with the permission of Ministries of Health and only under extraordinary circumstances (e.g. the insufficient supply of blood in the country can pose a risk to the health status of the population). The long-term aim of the Stability Pact for Social Cohesion blood safety project (previously quoted) is to increase the availability and acceptability (harmonized quality requirements) of safe blood for medical emergencies and special circumstances, as well as of the rare blood types, in the concerned countries.

\section{Challenges Ahead}

Important progress has been achieved in strengthening the safety of the blood supply in Bulgaria, Croatia, Romania, Serbia and Montenegro. Nevertheless, efforts are required to complete the process of development and harmonization of a legislative and regulatory framework and its implementation $[2,5,7,9]$. EU enlargement enhances the political momentum for sustainable change. High-level commitment is expected to translate into adequate funding and integration of the restructuring process within the health system framework.

Quality management systems need to be further developed and implemented at institutional level on a national basis. Ensuring quality and safety - a major task for blood and hospital services - can be supported by appropriate training and distribution of staff (and facility refurbishment as necessary). Increasing awareness and development of national hemovigilance programs requires agreement on a common taxonomy building on existing practices and an institutionalized, regulated agenda. Reinforcement of information technology is needed to ensure traceability, identification and shared network-based information providing support for national databases and donor registers [4].

The World Blood Donor Day event is expected to contribute to increasing awareness on the importance of voluntary blood donation and to enhance development of sustainable blood donor programs including regular promotion and education campaigns. Twinning programs and networking, such as the blood project within the South East Europe Stability Pact for Social Cohesion, are good practical examples of enhanced communication. Such initiatives are extremely valuable as a platform for collaboration and information exchange, and fostering regional harmonization.

\section{Acknowledgements}

The authors are grateful to Prof. Andrei Andreev and Dr. Svetla Bakalova, National Center for Hematology and Transfusion, Sofia, Bulgaria, Dr. Irena Iukic, Croatian Institute for Blood Transfusion, Zagreb, Croatia, Dr. Florentina Vladareanu, National Institute for Hematology and Blood Transfusion, Bucharest, Romania, and Dr. Snejana Draskovic and Prof. Gradimir Bogdanovic, National Blood Transfusion Institute, Belgrade, Serbia, for their important contributions to this article.

\section{References}

1 Directive 2002/98/EC of the European Parliament and of the Council setting standards of quality and safety for the collection, testing, processing, storage and distribution of human blood and blood components and amending Directive 2001/83/EC, Brussels, 2002.

2 WHO resolution EUR/RC55/R8: Strengthening European health systems as a continuation of WHO Regional Office for Europe's Country Strategy 'Matching Services to New Needs', 2005.

3 WHO Aide memoire for national blood programmes: Blood safety. WHO, BCT, 2002.

4 WHO Aide memoire for national blood programmes: Quality systems for blood safety. WHO, BCT, 2002.

5 Report: Seminar on governance principles for the blood transfusion service, Bucharest, October 2004. WHO Regional Office for Europe, 2005.
6 The Dubrovnik Pledge: Stability pact for South Eastern Europe, social cohesion initiative. WHO Regional Office for Europe, 2001.

7 Report: 2nd regional meeting of project managers South East European Health Network, stability pact for social cohesion - blood safety project, $\mathrm{Za}$ greb, October 2005. WHO Regional Office for Europe, 2006.

8 Van der Poel CL, Janssen MP: Final report - the collection, testing and use of blood and blood products in Europe in 2003. Council of Europe, October 2004-April 2005

9 Voljc B, Rossi U: Reality and prospects for the general organization of transfusion medicine services in SE Europe; in Rossi U, Aprili G (eds): Present and Future Problems of Transfusion Medicine in South Eastern Europe. Lecce ESTM Course Proceedings. Milan, SIMTI, 2002.
10 WHA.R58/13: Blood safety: proposal to establish World Blood Donor Day. The Fifty-eighth World Health Assembly, 2005.

11 Bakalova S: Transversal analysis of some aspects of the contribution of clinical medicine to blood safety in SE Europe; in Walterova L, Kretchmer V, Bogdanovic G, Rossi U (eds): The Contribution of Clinical Medicine to Blood Safety. Belgrade ESTM Course Proceedings. Milan, SIMTI, 2003.

12 The Economist: World in Figures. London, Profile Books Ltd. assoc. with The Economist, 2005. 